\title{
2D InP photonic crystal fabrication process development
}

\author{
Bifeng Rong ${ }^{\mathrm{a}^{*}}$, Emile van der Drift ${ }^{\mathrm{a}}$, Rob W. van der Heijden ${ }^{\mathrm{b}}$, Huub W. M. Salemink ${ }^{\mathrm{a}}$ \\ ${ }^{a}$ Kavli Institute of Nanoscience, Faculty of Applied Sciences, Delft University of Technology, \\ P. O. Box 5053, 2600 GB Delft, the Netherlands \\ ${ }^{\mathrm{b}}$ COBRA Inter-University Research Institute, Eindhoven University of Technology, P. O. Box 513, \\ $5600 \mathrm{MB}$ Eindhoven, The Netherlands
}

\begin{abstract}
We have developed a reliable process to fabricate high quality 2D air-hole and dielectric column InP photonic crystals with a high aspect ratio on a STS production tool using ICP $\mathrm{N}_{2}+\mathrm{Cl}_{2}$ plasma. The photonic crystals have a triangular lattice with lattice constant of $400 \mathrm{~nm}$ and air-hole and dielectric column radius of $120 \mathrm{~nm}$. Large efforts have been devoted on developing a proper mask. We obtained a perfect, clean and vertical profiled $\mathrm{SiN}_{\mathrm{X}}$ mask. The next main effort is InP pattern transfer in $\mathrm{Cl}_{2}+\mathrm{N}_{2}$ plasma. Etching selectivity, smooth sidewall and etch profile are directly related to plasma process condition, besides the quality of $\mathrm{SiN}_{\mathrm{X}}$ mask. We have optimized the $\mathrm{N}_{2}+\mathrm{Cl}_{2}$ plasma condition to obtain high aspect ratio, vertical profile and smooth sidewall InP structures. Cylindrical holes ( 2 micron depth) and rodlike pillars (2.4 micron height) are uniformly fabricated. An aspect ratio of 18 for $100 \mathrm{~nm}$ trench lines has been obtained. AFM measurement evidences that etched surfaces are smooth. The root mean square roughness of pillar and hole is 0.7 $\mathrm{nm}$ and $0.8 \mathrm{~nm}$, respectively. The optical transmission characterization of ridge waveguides has been carried out. Transmission spectrum of 1 micron wide waveguide has been obtained.
\end{abstract}

Keywords: Nanophotonics, nanophotonic crystal, III-V photonic crystal, InP nanophotonic crystal, high aspect ratio, 2D photonic crystal, gratings, hole and pillar, $\mathrm{Cl}_{2}+\mathrm{N}_{2}$ plasma, Nanofabrication, Nanotechnology

\section{INTRODUCTION}

Nanoscale optical devices have great potential to play a key role in future information processing technologies ${ }^{1}$ e.g. optical waveguide is kept as a standard connector on a laptop computer. As the frequency band of the internet continues to exponentially increase with time, smaller and faster optical components will be necessary to accommodate with this speed $^{2}$. InP is of particular interest because monolithic integration of optical functions with other optoelectronic devices on the same chip is possible.

However, one of the main barriers to the InP photonic devices is the difficulty in the fabrication ${ }^{3}$. A high aspect ratio is required for the photonic crystal structures. Further, the uniformity, irregularity and sidewall smoothness in fabricated structure limit the quality factor. There are many general studies on etching InP of large-scale structures ${ }^{4-5}$. Chen et $\mathrm{al}^{6}$ and Feurprier ${ }^{7}$ studied the etch mechanism of a ICP plasma using $\mathrm{CH}_{4}+\mathrm{H}_{2}$ chemistry. Whelan ${ }^{8}$ concluded that $\mathrm{CH}_{4}+\mathrm{H}_{2}$ produces high etch rate and smooth etched surface. By contrast, Lee et al ${ }^{9}$ suggested that both $\mathrm{Cl}_{2}$ and $\mathrm{CH}_{4} / \mathrm{H}_{2}$ based chemistry are not suitable for etching In-containing material such as InP, InAs and related alloys. They mentioned that $\mathrm{InCl}_{\mathrm{x}}$ etch products have relatively low volatilities and the $\mathrm{CH}_{4}+\mathrm{H}_{2}$ plasma chemistry produces very low etch rates.

While dry etching of micron-size InP structures has developed into routine, dry etching of high aspect ratio nanostructure, such as nano-photonic crystal (PC) is totally different. Effects like shadowing, aspect ratio dependent etching (ARDE), mask erosion and electrostatic deflection of incoming ions in the holes make plasma etching of PC very critical. PCs require high aspect ratio, vertical profile and smooth sidewalls. Many efforts to solve this problem can be seen from numerous of publications regarding InP nanostructure holes/pillar fabrication. Although holes with a depth of

*b.rong@tudelft.nl

Nanoengineering: Fabrication, Properties, Optics, and Devices III

edited by Elizabeth A. Dobisz, Louay A. Eldada, Proc. of SPIE Vol. 6327

632715, (2006) - 0277-786X/06/\$15 - doi: 10.1117/12.680281

Proc. of SPIE Vol. $6327632715-1$ 
3 micron and a depth to diameter ratio (aspect ratio) of 10 have been realized, the shape is usually tapered. It has been shown that the depth and profile of etched holes significantly affect the optical properties of PC based structure, in particular the propagation losses of PC waveguides ${ }^{10}$.

Nevertheless, some groups have succeeded in fabricating deep PC holes by $\mathrm{SiCl}_{4}$ chemistry. Djoudi et al ${ }^{11}$ first obtained a aspect ratio as high as 14 for a hole diameter varying from $200 \mathrm{~nm}$ to $240 \mathrm{~nm}$. Afterwards, Van der Heijden ${ }^{12}$ and Carlstrom et $\mathrm{al}^{13}$ have fabricated hole type photonic crystal using ICP at 250 degree with a $\mathrm{Cl}_{2}+\mathrm{O}_{2}$ gas mixture. Although the depth and steepness are significant, the root square roughness (rms) value of internal sidewall of these deep holes were not reported. Furthermore the narrow process window of the $\mathrm{Cl}_{2}+\mathrm{O}_{2}$ ICP causes process difficulties of differently scaled structures in a single pattern. Different structure sizes in one pattern are often the case for optical devices. For instance, a simple PC waveguide, the structures includes nano-size PCs about 200-240nm and micron-size waveguides. The width of air space on both sides of waveguide is often 10 to 20 micron. An effect like shadowing requires, obviously, different plasma tuning for smaller and larger structures, unless the process window is large enough to account for the range involved. As a consequence, if one optimizes the plasma conditions for the PCs, then the sidewall of waveguides may be very rough and/or under etched, because excessive incoming ions from angle will destroy the sidewall passivation. The chemical etching of the waveguide will in the worse case open the waveguide in some parts. On the other hand if one optimizes the plasma condition for the waveguide, the PCs (sidewall and bottom) will be over passivated and result in a tapered profile.

From a practical application point of view, the InP material system is relevant for telecommunication with a free space wavelength of 1.55 micron. To obtain a wide photonic band gap centered at 1.55 micron, a triangular lattice PC with lattice constant of $400 \mathrm{~nm}$ and hole/pillar diameter of $240 \mathrm{~nm}$ is required. For the vertical confinement, a lay structure consist of $500 \mathrm{~nm}$ cladding layer on top of $500 \mathrm{~nm}$ core layer has been widely employed. This indicates that 1.5 micron depth of PCs, holes or pillars with a diameter of $240 \mathrm{~nm}$ is required. It is pointed out that for a good PC performance, a vertical profile and a smooth sidewall are essential.

In this paper, we will report a reliable process for fabrication of high aspect ratio 2D InP PCs, both pillar and hole with vertical profile and smooth sidewall. In section 2, we will give the details of the experimental set up. In section 3, we will discuss the mask fabrication, dry etching process results and the AFM verification of sidewall roughness. Optical characterization of ridge waveguides will be presented in section 4, with the conclusions given in section 5 .

\section{EXPERIMENTAL}

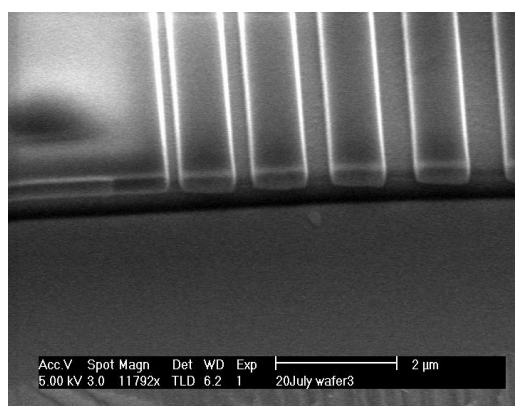

1a

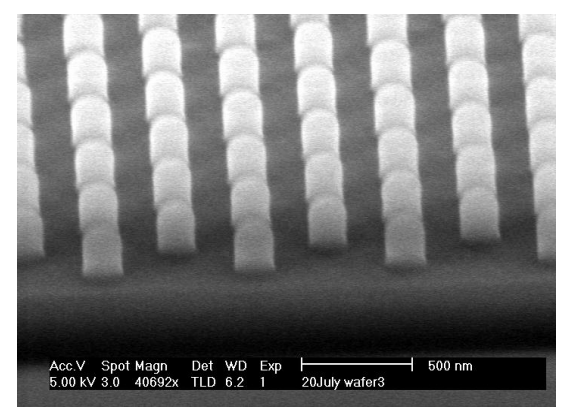

$1 \mathrm{~b}$

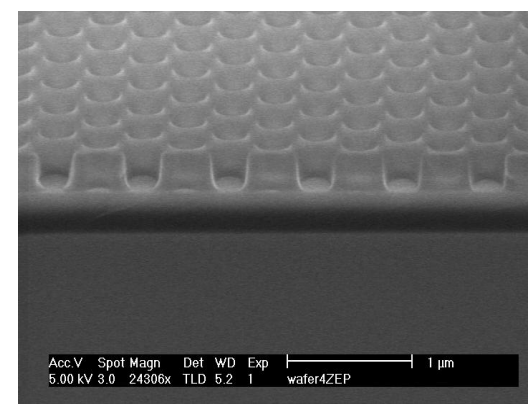

$1 \mathrm{c}$

Fig. 1. Cross section of the resist mask of 1a) trench lines with width varied from $100 \mathrm{~nm}$ to $500 \mathrm{~nm}$ and a space of $1 \mathrm{micron}$ in between, 1b) the pillar lattice with $\mathrm{a}=400 \mathrm{~nm}$ and $\mathrm{r}=120 \mathrm{~nm}$ and $1 \mathrm{c}$ ) holes lattice with $\mathrm{a}=400 \mathrm{~nm}$ and $\mathrm{r}=120 \mathrm{~nm}$. The micrographs are from a sample 60 degree titled. 
All the experiments were performed on (100) n-type Sn-doped InP samples. A layer of $550 \mathrm{~nm}$ low stress $\operatorname{SiN}_{X}$ has been deposited by PECVD on the InP samples, this $\mathrm{SiN}_{\mathrm{X}}$ layer serves as a mask layer for InP pattern transfer. Positive resist ZEP with a thickness of 500nm baked at 175 degree for 30 minutes is used for the e-beam pattern definition with the EBPG 5000+ from Leica. Fig. 1 shows the cross section of ZEP resist pattern after development. Fig. 1a shows lines with width of $100 \mathrm{~nm}$ up to 1 micron with a space of 1 micron in between. Fig $1 \mathrm{~b}$ and $1 \mathrm{c}$ show the triangular lattices of pillar and hole respectively, with a lattice constant of $400 \mathrm{~nm}$ and radius of $120 \mathrm{~nm}$. Obviously the e-beam writing dose and developing time have been optimized to get vertical resist profiles.

Then the pattern transfer into $\mathrm{SiN}_{\mathrm{X}}$ mask layer has been carried out by using $\mathrm{CHF}_{3} / \mathrm{Ar} \mathrm{RIE}$ plasma. The $\mathrm{CHF}_{3}$ is used to etch the $\mathrm{SiN}_{\mathrm{X}}$, the $\mathrm{Ar}$ is added to remove excessive $\mathrm{CF}_{\mathrm{X}}$ polymers from the etched surface. After having an over etch of the $\mathrm{SiN}_{\mathrm{x}}$ for a couple of minutes, the $\mathrm{CF}_{\mathrm{X}}$ polymer and ZEP residues are stripped off from the $\mathrm{SiN}_{\mathrm{X}}$ mask to get a clean surface. This is important because remainders will seriously affect the plasma etch result of the InP. The details about obtaining a perfect $\mathrm{SiN}_{\mathrm{X}}$ mask will be presented in section 3.1.

The final pattern transfer into InP has been carried out in a PECVD/ICP cluster tool from STS using $\mathrm{N}_{2}+\mathrm{Cl}_{2}$.gas mixture. A 4 inch silicon wafer has been employed as a carrier. A InP sample is then placed on the carrier to perform the pattern transfer. InP dummies have been placed around the sample to simulate the production environment. A He back flow of $14 \mathrm{mT} / \mathrm{min}$ has been maintained to keep good thermal contact between the carrier and chuck. The wafer is clamped to the chuck by using electrostatic clamping. All ICP etching experiments were performed at an elevated temperature of 160 degree, unless mentioned otherwise.

Atomic Force Microscope (AFM) from Park scientific instrument has been employed to measure the rms roughness of the internal wall of hole and sidewall of pillar. We used the contact mode. For the pillar, the AFM measurement is relatively simple. To characterize the internal wall of the holes, we have to cleave the sample in such a way that one half of the cleaved hole is deeper and the other half is shallow. Fig. 2 is the schematic drawing of the shallow half. The shallow halves with a depth of $d \leq 80 \mathrm{~nm}$ have been chosen for the hole internal wall characterization to exclude any unwanted interference from the cone of the AFM tip.

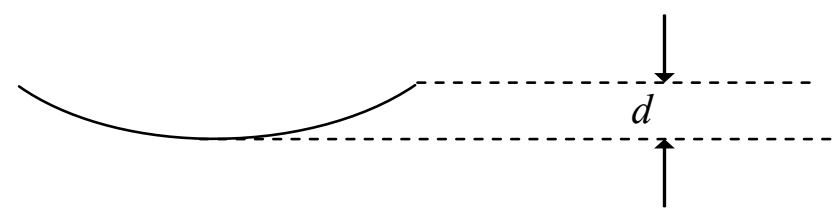

Fig. 2. Schematic drawing of the shallow half of the cleaved hole chosen for internal wall characterization to exclude any unwanted interference from the cone of the AFM tip.

For the optical experiments with sufficient vertical confinement a waveguide structure consisting of $500 \mathrm{~nm}$ InGaP (cone layer) and a $500 \mathrm{~nm}$ InP upper cladding layer have been used. Ridge waveguides with width varied from 1 micron to 5 micron have been fabricated. The transmission intensity has been measured. The range of waveguides has been fabricated on one sample in parallel with a pitch of 100 micron. The two ends of all waveguides have then been cleaved at both sides along a single plane (facet) before the sample is being mounted for optical characterization. It is reasonable for us to assume that the process induced roughness on sidewall and length are the same for all waveguides. The diameter of the in-coupling laser beam is about 1.5 micron. The light source has been TE polarized before coupled into the sample. The wavelength range of the light source is from $1470 \mathrm{~nm}$ to $1570 \mathrm{~nm}$. 


\section{DRY ETCHING RESULTS AND DISSCUSSION}

\section{1 $\mathrm{SiN}_{\mathrm{X}}$ mask}

To fabricate a high quality nano-PCs with lattice constant of $400 \mathrm{~nm}$ and hole/pillar diameter of $240 \mathrm{~nm}$, a vertical profile and smooth internal surface are required, besides the high aspect ratio. The verticality of profile, smoothness of sidewall and regularity of PCs are directly related to the quality of the $\mathrm{SiN}_{\mathrm{X}}$ mask. This is because any imperfection of the mask will be amplified into the InP structure during pattern transfer, for instance a tapered mask reduces ion shadowing and induces faceting and bowing.

Fig. $3 a, 3 b$ and $3 c$ are the SEM images of the $\mathrm{SiN}_{\mathrm{X}}$ mask cross section after the $\mathrm{CHF}_{3} / \mathrm{Ar}$ plasma etching with the residual ZEP still on top. The profiles are vertical. The advantage of ZEP is the high resolution; however, its disadvantage is flake like residuals. From fig. 3b, one can see clearly that some of the flakes on the pillars are stretched out. ZEP has been hard baked at 175 degree for a half hour as mentioned in section 2 . The residuals will act as a micron mask which results in a rough etched surface and irregularity of pillars. The same thing is happening to gratings and holes.

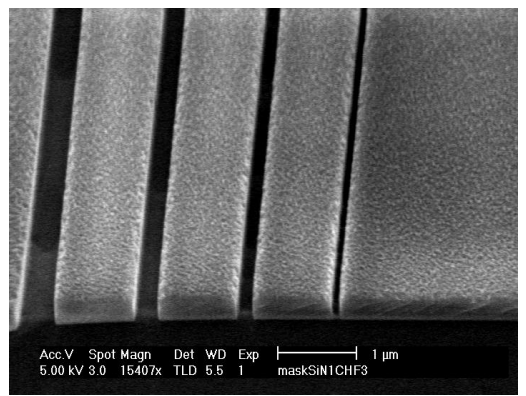

$3 \mathrm{a}$

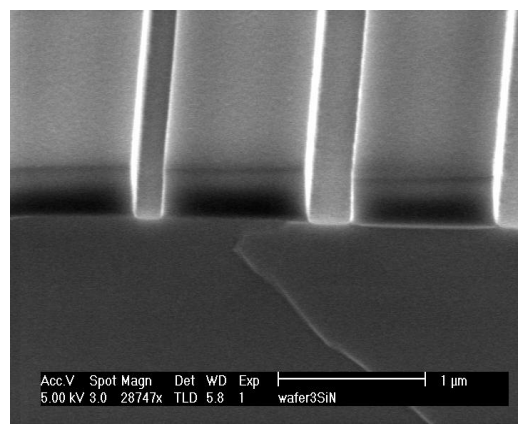

$3 \mathrm{~d}$

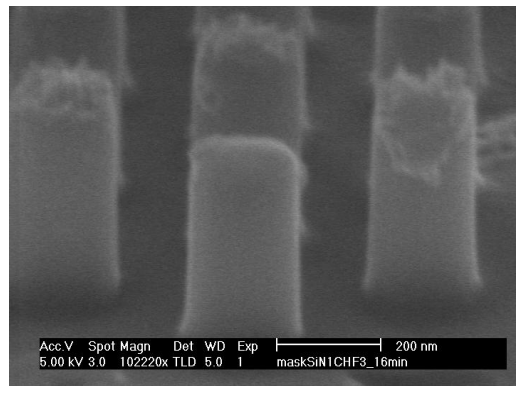

$3 \mathrm{~b}$

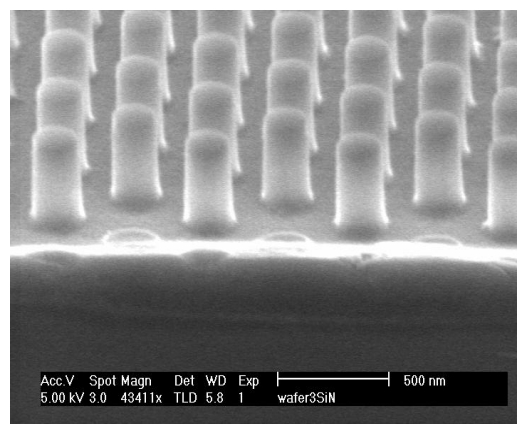

$3 e$

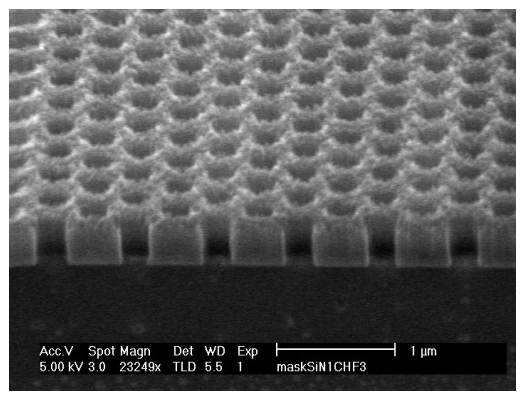

$3 \mathrm{c}$

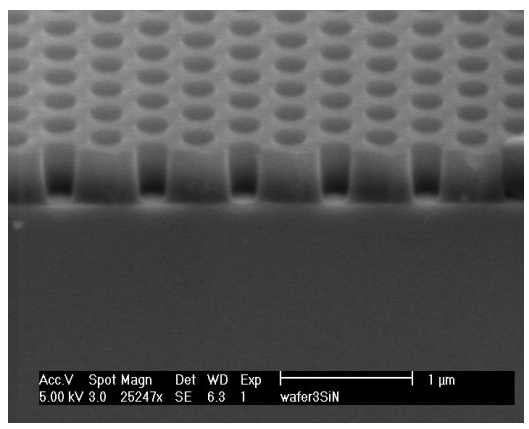

$3 \mathrm{f}$

Fig. 3. Cross sections of $\operatorname{SiN}_{x}$ mask before (3a, 3b, 3c) and after (3d, 3e, 3f) wet chemical etching respectively. In (3a, 3d) trench lines with a width range from $100 \mathrm{~nm}$ to 1 micron and with a space of 1 micron in between, in (3b, 3e) the pillar lattice with $\mathrm{a}=400 \mathrm{~nm}$ and $\mathrm{r}=120 \mathrm{~nm}$ and in $(3 \mathrm{c}, 3 \mathrm{f})$ hole lattice with $\mathrm{a}=400 \mathrm{~nm}$ and $\mathrm{r}=120 \mathrm{~nm}$. Obviously, the mask is clean and perfect after the wet etching. The micrographs are performed from a sample 60 degree titled.

There are a couple of ways to remove the ZEP residuals. A normal procedure like ashing does not work because ZEP is a silicon containing resist. After a few experimental tests with different methods, we found that wet chemical etching of PRS3000 at elevated temperature about 70 degree was the best solution. Fig. 3d, 3e and 3f show the perfect, clean and vertical profiled SiNx mask, where ZEP residuals have been removed by wet chemical PRS3000 etching. 


\subsection{InP pattern transfer in ICP $\mathbf{N}_{2}+C_{2}$ plasma}

Next main effort is an InP pattern transfer in a $\mathrm{N}_{2}+\mathrm{Cl}_{2}$ plasma. Criteria for etching selectivity, sidewall roughness and etching profile determine a plasma process window.

Throughout we used a mixture of $\mathrm{N}_{2}+\mathrm{Cl}_{2}$ gas to etch InP. First we have scanned the ratio in the gas mixture while keeping the rest of parameters constant. The etch rate increases with increasing $\mathrm{Cl}_{2}$ flow. Pure $\mathrm{Cl}_{2}$ produces the highest etch rate, but a high $\mathrm{Cl}_{2}$ fraction also causes lateral etching and a rough etched surface, the latter due to nonstoichiometric etching of the constituting elements. With increasing the $\mathrm{N}_{2}$ fraction, both the lateral etching and vertical etching decrease, while the etched surface gets smoother. We found that at around $\mathrm{N}_{2}: \mathrm{Cl}_{2}=3: 1$ the chemical component and physical component start to be balanced in such a way that the profile is vertical, the etched surface is to be clean and the etch rate is still reasonable. In $\mathrm{N}_{2}+\mathrm{Cl}_{2}$ plasma, nitrogen mainly plays a passivation role to prevent the lateral etching. On the other hand, $\mathrm{N}_{2}$ also passivates the bottom and this slows down the vertical etch rate. At $\mathrm{N}_{2}: \mathrm{Cl}_{2}=3: 1$, the $\mathrm{N}_{2}$ passivation is sufficient. The etch profile is vertical and the etched surface is smooth with a reasonable etch rate. In the remainder etch experiments have been carried out in a $\mathrm{N}_{2}: \mathrm{Cl}_{2}=3: 1$ gas mixture.

The etch pressure is an important parameter. Basically at very low pressure, the ion current density is relatively high, while the chemical component becomes the limiting factor. Vice versa at a high pressure the chemical component is dominant and the ion flux becomes the limiting factor. We have varied pressure from $1.6 \mathrm{mT}(0.2 \mathrm{~Pa})$ to $3.8 \mathrm{mT}(0.5 \mathrm{~Pa})$ in a $\mathrm{N}_{2}: \mathrm{Cl}_{2}=3: 1$ plasma. The fastest etch rate was found at $2.3 \mathrm{mT}(0.3 \mathrm{~Pa})$, which is a balance point of chemical etching and physical sputtering in our STS-ICP $\mathrm{N}_{2}: \mathrm{Cl}_{2}=3: 1$ plasma. Thus, etch pressure of $2.3 \mathrm{mT}$ has been defined

The ICP source power has been varied from $400 \mathrm{~W}$ to $800 \mathrm{~W}$, while keeping the other parameters constant, i.e. platen power of $60 \mathrm{~W}$, etch pressure of $2.3 \mathrm{mT}$, temperature of 160 degree and etch time of 5 minutes. The etch rate increases slightly with increasing ICP source power. On the other hand, the profile is getting slightly more vertical with decreasing ICP source power. This can be seen from holes depth/pillar heights and their profiles. The pillar in fig. $4 \mathrm{a}$ is etched with ICP source power of $800 \mathrm{~W}$ and pillar in fig. $4 \mathrm{~b}$ is etched with ICP source power of $400 \mathrm{~W}$. Obviously the pillar in Fig. $4 \mathrm{a}$ is higher than that in fig. 4b. In general, the profiles in both cases are good and the sidewalls are smooth. This implies that the process window is large. However, the profile of pillar in fig. $4 \mathrm{~b}$, especially the low part of the pillar has a better verticality than that in Fig. 4a. Nevertheless, the profile of $800 \mathrm{~W}$ is still reasonable good and with a relative higher etch rate. Thus, we keep the ICP source power at $800 \mathrm{~W}$ for the rest of the experiments.

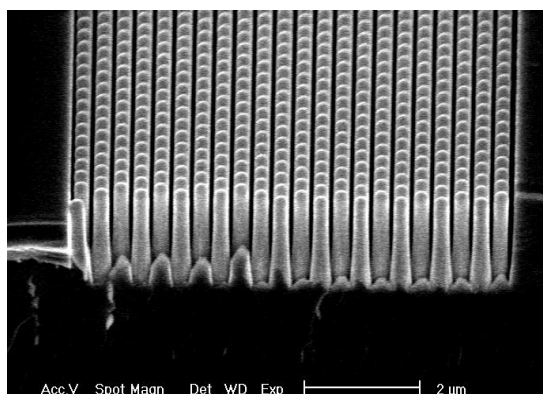

$4 \mathrm{a}$

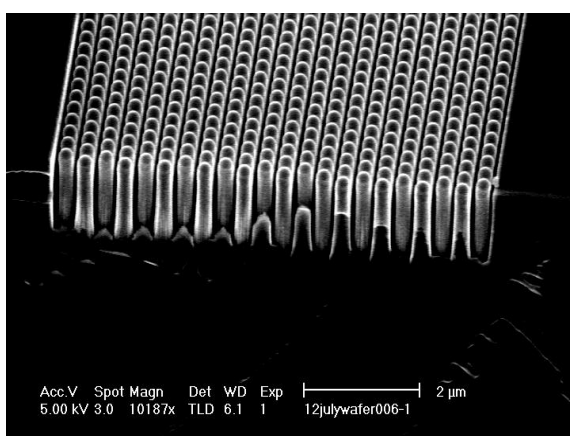

$4 \mathrm{~b}$

Fig. 4. Cross section of InP pillars etched at 4a) ICP source power of $800 \mathrm{~W}$ and $4 \mathrm{~b}$ ) ICP source power of $400 \mathrm{~W}$, while the other parameters are constant, platen power of $60 \mathrm{~W}$, etch pressure of $2.3 \mathrm{mT}$, temperature of 160 degree and etched time of 5 minutes. The micrographs are performed from a sample 60 degree titled. 
We have also looked at the platen power. The platen power is mainly changing the DC bias voltage. Platen power/DC bias does not play an important role on the etch rate in this process. However, the DC bias does have a significant influence on the profile verticality and mask selectivity. We varied platen power from $60 \mathrm{~W}$ to $150 \mathrm{~W}$, while keeping the rest of parameters constant, i.e. ICP source power of $800 \mathrm{~W}$, etch pressure of $2.3 \mathrm{mT}$, temperature of 160 degree and etch time of 5 minutes. Fig. $5 \mathrm{a}$ and $5 \mathrm{~b}$ show the pillars etched with the platen power of $150 \mathrm{~W}$ and $80 \mathrm{~W}$ respectively. As mentioned previous that pillar in fig. $4 \mathrm{a}$ has been etched with platen power of $60 \mathrm{~W}$. Obviously the pillar profile in fig. $5 \mathrm{a}$ is tapered and the sidewall is rough, especially at the bottom part of the pillar. Further more the mask selectivity is small. The pillar profile in fig. $5 \mathrm{~b}$ is vertical and the sidewall is smooth, which is similar to that in fig. 4a. Again this indicates a large process window.

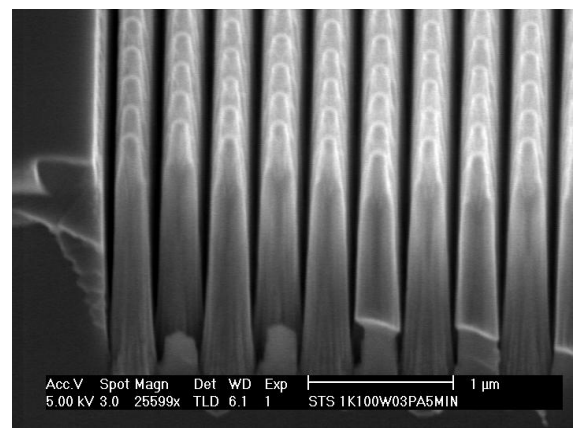

$5 \mathrm{a}$

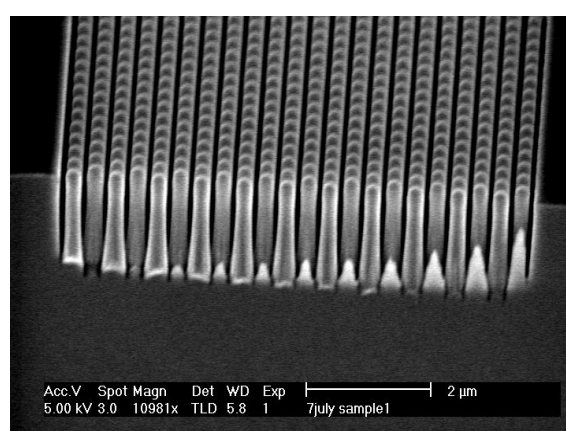

$5 b$

Fig. 5. Cross section of InP pillars etched at 5a) platen power of $150 \mathrm{~W}$ and $5 \mathrm{~b}$ ) platen power of $800 \mathrm{~W}$, while the other parameters are constant, ICP source power of $150 \mathrm{~W}$, etch pressure of $2.3 \mathrm{mT}$, temperature of 160 degree and etched time of 5 minutes. The micrographs are performed from a sample 60 degree titled.

We varied the etching temperature from 100 degree to 170 degree, since the maximum temperature is 180 degree for STS-ICP. The etch rate increases slightly with temperature, while the lateral etching also increase slightly. The summary of etch parameters effect of etch rate and profile has been listed in table 1.

Table 1 Etch parameters effect the etch profile and etch rate

\begin{tabular}{|l|l|c|}
\hline Parameters & Profile & Etch rate \\
\hline Cl flow & Lateral & $\mathbf{4}$ \\
\hline Pressure & & $\downarrow \mathbf{4}$ \\
\hline DC bias & Vertical & $\rightarrow$ \\
\hline ICP source power & & $\rightarrow$ \\
\hline Temperature & & $\rightarrow$ \\
\hline Paten power & & $\rightarrow$ \\
\hline
\end{tabular}

:means increase

:means significant increase with the parameter increasing

:means decrease

:means no significant increase with the parameter increasing 
Along all these parameter we have optimized the $\mathrm{N}_{2}+\mathrm{Cl}_{2}$ plasma towards a balance between chemical etching and ion sputtering. In this way we have obtained high aspect ratio, vertical profile and smooth sidewall InP structures. The optimum settings are an source power of $800 \mathrm{~W}$, a platen power of $100 \mathrm{~W}$, an etching pressure of $2.3 \mathrm{mT}$, a temperature of 160 degree and an etch time of 8.5 minutes for the given $550 \mathrm{~nm} \mathrm{SiN} \mathrm{X}_{\mathrm{X}}$ mask. The etch results are shown in Fig. 6. Cylindrical hole ( 2 micron depth) and rodlike pillar (2.4 micron height) are uniformly fabricated. Their high-resolution images show that the sidewalls are smooth. An aspect ratio of 18 for $100 \mathrm{~nm}$ trench lines has been obtained as shown in Fig.7.

Moreover, the advantage of this process is that it can be applied to differently scaled structures in a single pattern because of its large process window. The developed process is reliable and reproducible and ready for industry application.

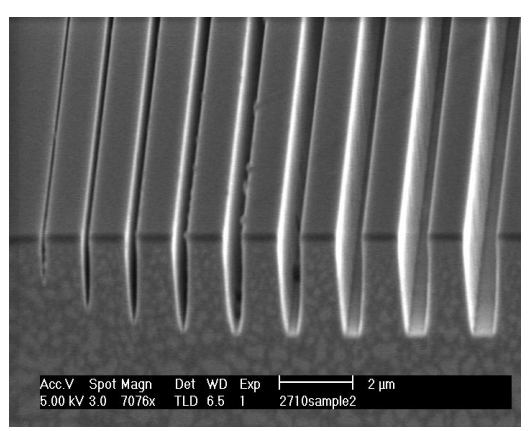

$6 a$

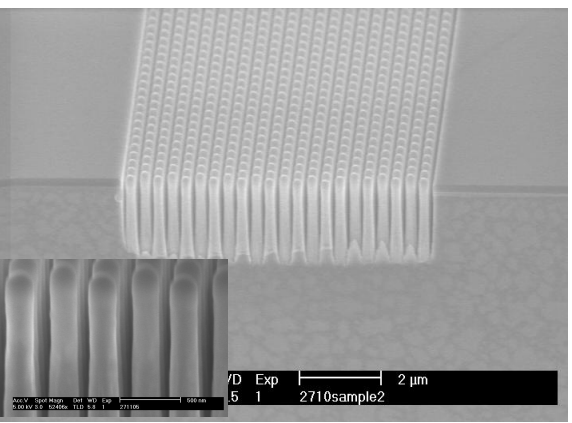

$6 b$

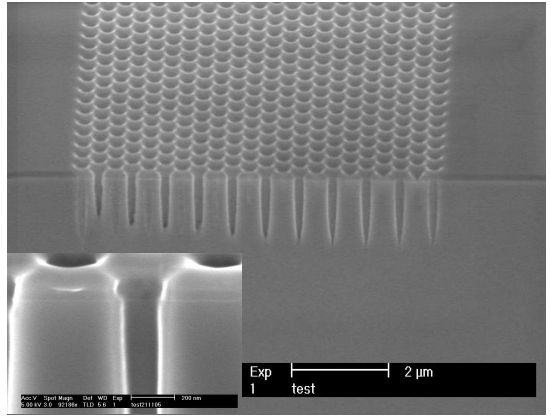

$6 c$

Fig. 6. shows the cross section of InP structures of $6 \mathrm{a}$ ) trench lines with the width from $100 \mathrm{~nm}$ to 1 micron, $6 \mathrm{~b}$ ) the rodlike pillars with $\mathrm{a}=400 \mathrm{~nm} \mathrm{r}=120 \mathrm{~nm}$ and height of about 2.4 micron and $6 \mathrm{c}$ ) cylindrical holes with $\mathrm{a}=400 \mathrm{~nm} \mathrm{r}=120 \mathrm{~nm}$ and depth of about 2 micron. The sample is 60 degree titled.

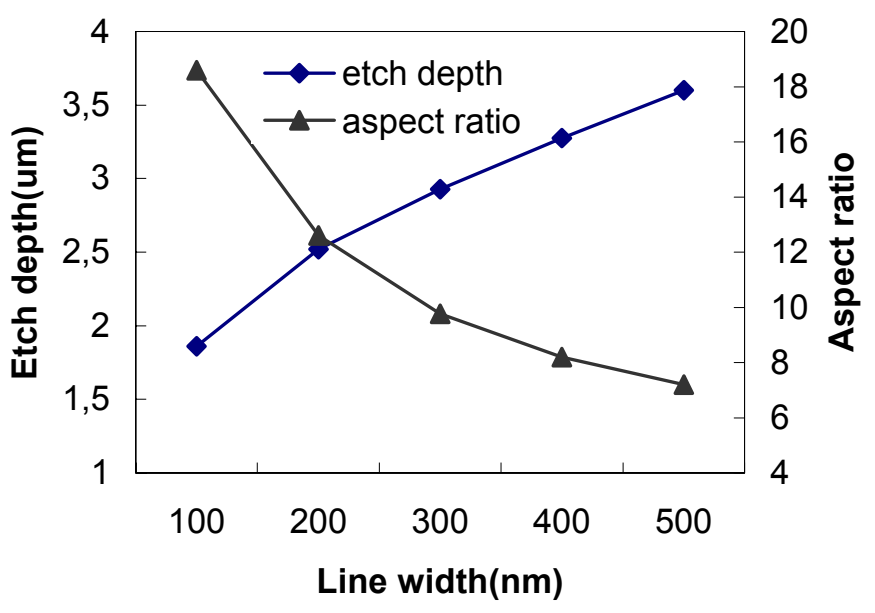

Fig. 7. Shows etch depth and aspect ratio vs. line width. The aspect ratio of 18 has been achieved with line width of $100 \mathrm{~nm}$ by developed process. The developed process on STS cluster tool is very promising for InP photonic device production. 


\subsection{AFM characterization}

A PC sidewall roughness in nanometer scale is required for PC application. The smooth etched sidewall of InP PCs has been evidenced by AFM measurement. Fig. 8 is 3 dimensional AFM images of pillar and hole from the same sample as shown in Fig. $6 \mathrm{~b}$ and $6 \mathrm{c}$. For rms roughness data process, first we have extracted a small square on top of the pillar and on the bottom of hole as shown in Fig. 8a and 8b. Then the extracted areas have been flattened. The rms roughness of InP pillar and internal sidewall of InP hole are $0.7 \mathrm{~nm}$ and $0.8 \mathrm{~nm}$ respectively. To the best of our knowledge this is the first time report of the AFM characterization on sidewall of 2D InP PCs, pillar and hole.

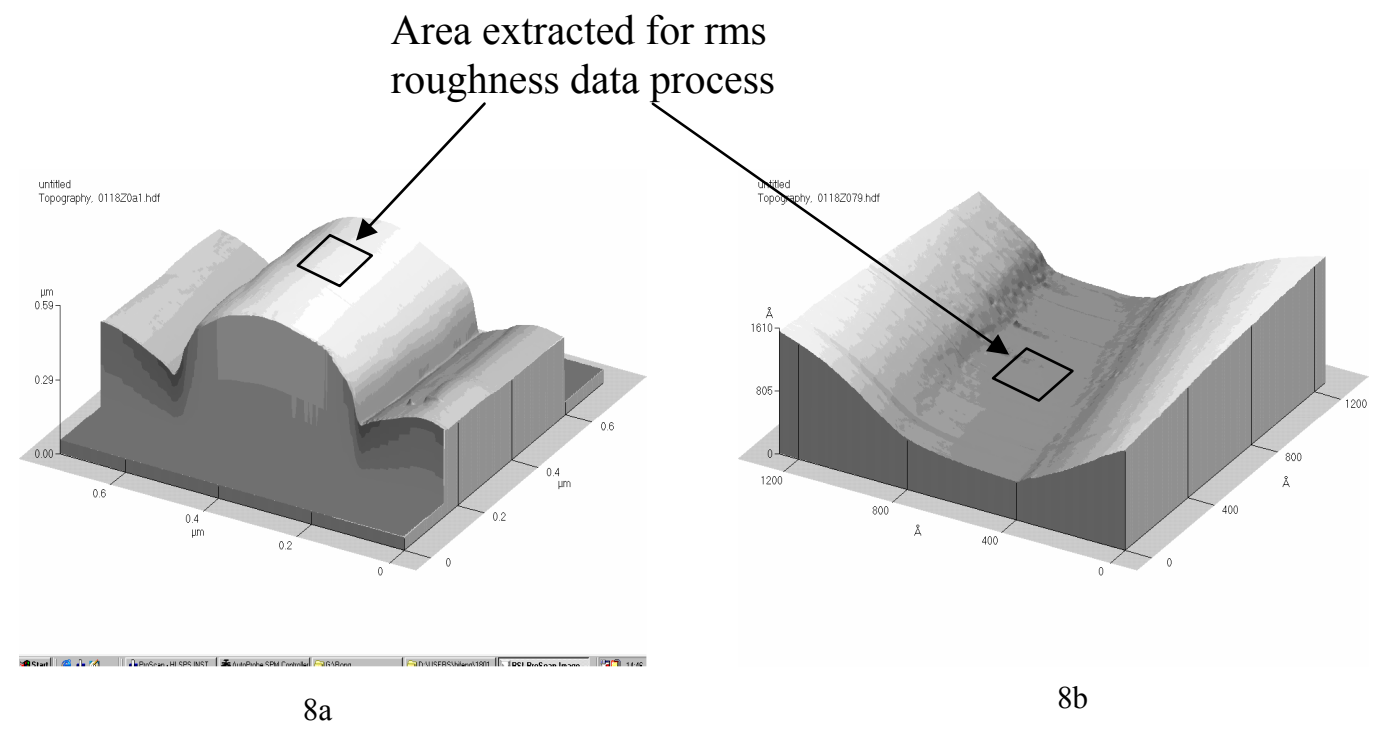

Fig. 8. 3D AFM image of InP 8a) InP pillar and 8b) InP hole from the same sample as shown in fig. $6 \mathrm{~b}$ and $6 \mathrm{c}$. The rms roughness of pillar and internal sidewall of hole is $0.7 \mathrm{~nm}$ and $0.8 \mathrm{~nm}$, respectively.

\section{OPTICAL RESULT}

To further verify the sidewall smoothness in a practical way, the optical characterization of ridge waveguides with different width has been carried out. The ridge waveguides with width of 1, 1.5, 2.5 and 5 micron have been fabricated on quaternary material. Fig. 9a shows the cross section of 1 micron wide ridge waveguide. The depth of the ridge is 4 micron. This depth is much larger than the diameter of in-coupling light beam size. The air space is 20 micron on both sides. Fig. $9 \mathrm{~b}$ is cross section of planar waveguide material stack, which consists of $550 \mathrm{~nm} \mathrm{SiN} \mathrm{X}_{\mathrm{X}}$ mask layer, $500 \mathrm{~nm} \mathrm{InP}$ capping layer(reflective index 3.17) and $500 \mathrm{~nm} \mathrm{InGaAsP}$ core layer (reflective index 3.34) and InP substrate from top.

The light source is TE polarized 1.55 micron wavelength. In the vertical direction the light is confined into the waveguide in a single mode by the material system. The condition of confinement in the vertical direction is given by,

$\lambda=\frac{2 L}{n}$

$\mathrm{n}=1,2,3 \ldots \ldots$ 
where $\lambda$ is the wavelength of lights coupled into $\operatorname{InP}$ waveguides and $\mathrm{L}$ is core layer thickness. In this case, the wavelength will be about 0.5 micron considering a reflective index of InP 3.25(average number).

Horizontal confinement is achieved through the geometry of the physical waveguide. However, the sidewall roughness induced by dry etching maybe an issue. Rough sidewall influences on sidewall scattering losses, when EM field is not zero at wall. The lowest mode has small amplitude at sidewall and will not scatter so severe. Higher order modes have large amplitudes at the sidewall and thus will strongly attenuate. For the single mode waveguide, only one transmission intensity peak can be detected. For multi-modes waveguide, more than one transmission intensity peaks can be detected.

During optical characterization of transmission spectra measurement, for the 1 micron ridge waveguide, only one intensity peak has been obtained, while the 1.5 micron ridge waveguide gives two intensity peaks. This implies that the 1 micron waveguide has single mode, while the 1.5 micron ridge waveguide gives multi-modes.

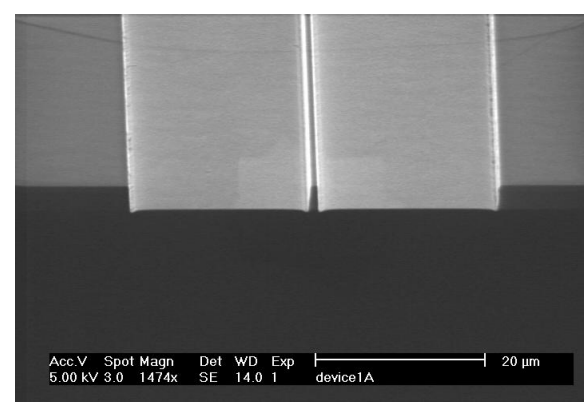

$9 \mathrm{a}$

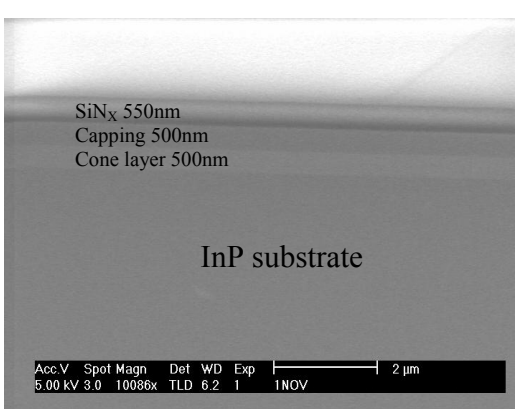

$9 \mathrm{~b}$

Fig. 9 Cross section of 9a) $1 \mu \mathrm{m}$ waveguide and 9b) planar waveguide material stack, which consists of 550nm SiN $\mathrm{n}_{X}, 500 \mathrm{~nm}$ InP cap, 500nm InGaAsP core and InP substrate (from top).

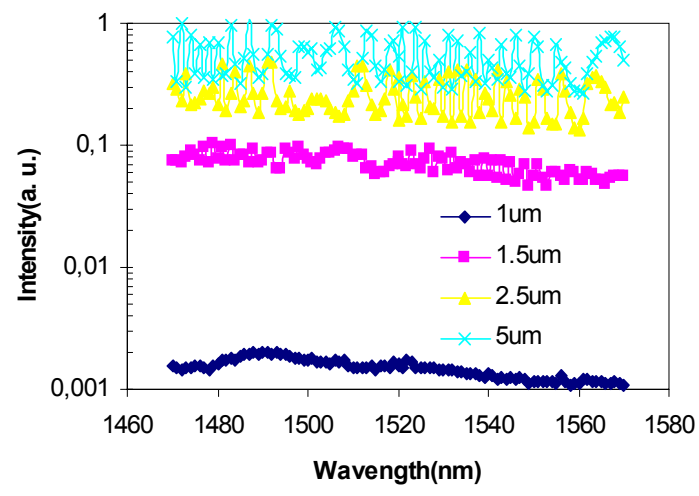

Fig. 10. Transmission spectra of ridge waveguides with width of $1,1.5,2.5$ and $5 \mu$ m respectively developed in $\mathrm{Cl}_{2}+\mathrm{N}_{2} \mathrm{ICP}$. The single mode on 1 micron waveguide and multi-mode on the rest of waveguides have been observed.

Fig.10 is the transmission spectra of the ridge waveguides. The intensity has been normalized. The 2.5 and 5 micron wide waveguides have received the maximum in-coupling of light; given the beam size is about 1.5 micron. These two waveguides have minimum coupling loss. As mentioned, the waveguides have the same length and have the same sidewall roughness. However, the EM-field factor is different on the wall for different width of waveguide. This results in slight larger scattering losses for the 2.5 micron waveguide. For 1.5 micron waveguides, some coupling loss can be 
expected because the width of waveguide is close to beam size, besides the sidewall roughness losses. Nevertheless, their intensities are all on the same order. The main losses of these waveguide are from high order modes scattering. The 1 micron waveguide is about 1000 time lower than the 5 micron one. There are two reasons; one is coupling loss as the waveguide is narrower than the beam size. The second reason is that this is a single mode waveguide. The roughness of sidewall is influencing on the fundamental mode.

\section{CONCLUSIONS}

We have developed a reliable, reproducible process using $\mathrm{N}_{2}+\mathrm{Cl}_{2}$ in STS-ICP for etching InP PCs. The plasma has been optimized into chemical etching and ion sputtering balanced regime to obtain high aspect ratio, vertical profile and smooth sidewall InP structures. Cylindrical hole ( 2 micron depth) and rodlike pillar (2.4 micron height) are uniformly fabricated. An aspect ratio of 18 for $100 \mathrm{~nm}$ trench lines has been obtained. The etched surface is smooth. This has been evidenced by AFM measurement. The rms of pillar surface and hole internal wall is about $0.7 \mathrm{~nm}$ and $0.8 \mathrm{~nm}$, respectively. The advantage of this process is that process window is very large, which makes it suitable for PC device fabrication. We have obtained transmission spectra of 1 micron wide waveguide for 1.5 micron wavelength light source.

\section{REFERENCES}

1. J. D. Joannopoulos, R. D. Meade and J. N. Winn "Molding the flow of light" Princeton University Press, New Jersey (1995)

2. G. L. Bona, R. Germann, and B. J. Offrein, Journal of Research and Development. 47(2/3) (2003) (internet)..

3. F. Gadot, A. Chelnokov, A. De Lustrac, P. Crozat, J.-M. Lourtioz,D. Cassagne and C. Jouanin Appl. Phys. Lett. 71(13), 1780-2 (1997)

4. J. M. Rossler, Y. Royter, D. E. Mull, W. D. Goodhue and C. G. Fonstad "Bromine ion-beam-assisted etching of InP and GaAs" J. Vac. Sci. Technol. B 16(3) 1012-1017 (1998)

5. K. Janiak and U. Niggebrugge "Investigation of macroscopic uniformity during $\mathrm{CH}_{4} / \mathrm{H}_{2}$ reactive ion etching of $\operatorname{InP}$ and its improvement by using of a guard ring" J. Vac. Sci. Technol. B 20(1), 105-108 (2002)

6. Hsin-Yi Chen and Harry E. Ruda "Inductively coupled plasma etching of InP using $\mathrm{CH}_{4} / \mathrm{H}_{2}$ and $\mathrm{CH}_{4} / \mathrm{H}_{2} / \mathrm{N}_{2}$ " J. Vac. Sci. Technol. B 20(1) 47-52 (2002)

7. Y. Feurprier, Ch. Cardinaud and G. Turban "Infleunce of the gas mixture on the reactive ion etching of InP in $\mathrm{CH}_{4}$ $\mathrm{H}_{2}$ plasma” J. Vac. Sci. Technol. B15(5), 1733-1740 (1997)

8. C. S. Whelan, T. E. Kazior and K. Y. Hur "High etch rate $\mathrm{CH}_{4}: \mathrm{H}_{2}$ plasma etch processes for InP" J. Vac. Sci. Technol. B 15(5) 1728-1732(1997)

9. J. W. Lee, J. Hong, E. S. Lambers and S. J. Pearton "ICP plasma etching of III-V semiconductors" J. Vac. Sci Technol. B 15(3) 652-656 (1997)

10. H. Benisty, D. Labilloy, C. Weisbuch, C. J. M. Smith, T. F. Krauss, D. Cassagne, A. Beraud and C. Jouanin, “ Radiation losses of waveguide-based two-dimensional photonic crystals: Positive role of the substrate" Apl. Phys. Lett. 76(5), 532-534, (2000)

11. A. Djoudi, L. Legouezigou, S. Hubert, S. Sainson, C. Moussant, J.-P. Chandouineau, F. Pommereau and G.-H. Duan, "Fabrication of two dimensional InP photonic band gap structures using inductively coupled plasma etching" IEEE Proceeding $14^{\text {th }}$ of IPRM conference, 429-432, (2002)

12. R. van der Heijden, M. S. P. Andriesse, C.-F. Carlstrom, E. van der Drift, E.-J. Geluk, R. W. Van der Heijden, F. Karouta, P. Nouwens, Y. S. Oei, T. Der Vries, H. W. M. Salemink. "deep dry etching process development for photonic crystals in InP based planar waveguides" Pro. of SPIE 5450 523-531(2004)

13. C. F. C. Carlstrom, R. van der Heijden, F. Karouta, R. W. van der Heijden, H. W. M. Salemink and E. van der Drift " $\mathrm{Cl}_{2} / \mathrm{O}_{2}$-Inductively coupled plasma etching of deep hole-type photonic crystal" J. Vac. Sci. Technol. B 24(1) 6-9, (2006) 